\title{
Measuring the Impact of the Paternal Leadership Style on Staff Performance at Company $\mathrm{X}$, Vietnam
}

\author{
Jared Potgieter*, Christo A. Scheepers \\ South Africa
}

*Corresponding Author: Jared Potgieter, South Africa

\begin{abstract}
This research investigated the effect of the paternal leadership style at Company X, Vietnam, had on staff performance. The research is based on the relationship between the paternal leadership style and how it impacts overall staff performance within the company. The research is centered on one company within Vietnam, who are to remain anonymous within this article. The sample size consisted of 60 employees, 30 of who were expats with the other 30 consisting of Vietnamese nationals. Findings indicate that there is an overall negative impact on staff performance based on the leadership style practiced at the company. Data had been collected through self-administered questionnaires and analyzed through the use of Google Forms. The results remain consist with previous research conducted as well as results received in the pilot study. The research aids prospective companies expanding to Vietnam as they are required to employ Vietnamese directors in their companies. This allows expanding companies a clear understanding of what kind of Leadership to expect within their companies.
\end{abstract}

Keywords: Paternal Leadership Style, Measuring, Staff Performance, Vietnam

Abbreviations: LSP: Leadership Styles Practiced; PLS: Paternal Leadership Style; BM: Branch Manager; CM: Customer Manager; OM: Operations Manager; JOM: Junior Operations Manager; FM: Faculty Manager; HT: Head Teacher

\section{INTRODUCTION}

There is a vast amount of research available in the West regarding the paternal leadership style, however this research is lacking most in the East, where the leadership style is most commonly practices. The aim of this study is to investigate the relationship between the paternal leadership style and staff performance at Company X, Vietnam.

This study will provide a measurement of the effects of the LSP as applied in Company X, and the impact thereof on staff performance. Leadership in Vietnam is considered a sacred role, usually directing the family or a group of people for the benefit of all as stated by Dang (2017). The patriarchal leadership style has been the most popular and common style practiced both socially and professionally in Vietnam since 1996 as stated by Be (2013). Since the South of Vietnam, Ho Chi Minh City. Formerly known as Saigon, has rapidly expanded and gained Western influence, resulting in a more supportive, democratic and coaching leadership role becoming prominent in the south as stated by be (2013). The LSP at Company X is best described as the PLS. The focus of the study is to measure the impact of the PLS on staff performance at Company X. This information will help identify the efficacies of the LSP and the deterrent factors as perceived by Vietnamese and foreign staff

In Company $\mathrm{X}$, a practice of what is known as the PLS is common throughout the company. The leadership style is enforced upon both local and international staff. Western theoretical or practical business leadership tend to have a monopoly within specific industries in Vietnam, and this is especially true for the South of Vietnam according to Meyer et al. (2015). The research will help Company $\mathrm{X}$ better understand what impact this leadership style has on foreign and local staff performance. Understanding the limitations and benefits of the PLS would help Company X better prepare for expansion and recruiting in Vietnam, as the leadership style itself is the perceived, most popular style in Vietnam as mentioned by Boer et al. (2013).

The LSP at Company X in Vietnam is centered on the PLS. According to Ngan et al. (2015), this leadership style is popular in Vietnam and grew in popularity after governmental changes in 
regulation in 1996. The PLS could lead to detrimental operations within a variety of departments and could deter foreign nationals from joining the Company $\mathrm{X}$ work-force and there may be potential areas within the Company $\mathrm{X}$ which could require some improvements. The research undertaking will measure the negative impact of the PLS within Company X for both foreign and local Vietnamese Staff performance.

\section{Materials \& MeTHODS}

\subsection{Research Methodology}

Descriptive research has been used in this research undertaking, due to it being the most efficient method to evaluate the data collected in the surveys and present the effects that the PLS has on staff performance at Company X. The positivism philosophy has been used as the most effective approach to assess the effects of the PLS effects on staff performance at Company X. A survey strategy was used for this research undertaking through the use of self-administered questionnaires and a quantitative research method was used for this research proposal as the research topic. The target population consisted of Vietnamese and Expats currently working at Company X in Vietnam. The age group targeted ranged between the ages of 21 and 45 . All candidates within the target population were working within the Education Industry in Vietnam. Sixty (60) Respondents were used in total within Company X. The sample consisted of thirty (30) Vietnamese locals and thirty (30) expats all working within Company X .Cluster sampling, has been used to measure the effects of the LSP in Company X.

\subsection{Data Collection}

Primary data was collected for the research undertaking through self-administered questionnaires. The questionnaires were created through the use of Google Forms. Administration of the questions have been done through emailing the questionnaires within the email itself to respondents and sharing the questionnaires through Slack, and company specific slack channels. Once the questionnaires were completed, all data was saved through the use of Google Forms. Google Forms for collection and analysis, as well as Microsoft Excel Spreadsheets to transpose information into a table format. The analyzed data was collected from questionnaires administered through the use of Google Forms, in both Email and communication software such as Slack. Limitations face during the study came from the one sample group, the sample, specifically Vietnamese respondents, would provide more positive feedback due to the survey being about Company X leadership and they're innate culture to conform for appeasement of leadership roles. Vietnamese respondents provided positive or neutral responses due to the fear of the results being seen by company leaders and the fear of specific staff being identified.

\section{RESULTS \& DISCUSSION}

The results gathered from the survey responses have been analyzed and interpreted by comparing responses between Vietnamese Nationals and expatriates living and working at Company $\mathrm{X}$.The research found that 20 percent of respondents have 3 years or more experience working at Company $\mathrm{X}$ where as 40 percent of respondents have been with the company for 1-to-2 years and another 40 percent have been with Company $X$ for less than 1 year. Further Research indicated that 31.7 percent of respondents are between the ages of 20-to-25. 46.7 percent of respondents were between the ages of 26 to 30, whereas 18.3 percent of respondents are between the ages of 31 to 39.3 .3 percent of staff at Company $\mathrm{X}$ are above the age of 40 .

Further results and discussions have been divided up into several sections

\subsection{Centered on Questions Impacting Staff Perception.}

$46.6 \%$ of respondents disagrees to varying extends that Vietnamese leadership take care of staff. $28.6 \%$ of respondents agreed to varying extents that leadership at Company $\mathrm{X}$ takes care of staff. Makaske (2015) states that varying staff needs attended to by corporate leaders yield better staff morale and overall performance. $46.6 \%$ of staff disagree to varying extents that company leaders attempt to understand the underlying cause to poor staff performance, where as $31.7 \%$ of respondents agree to varying extents that leadership at Company $\mathrm{X}$ strive to understand the cause to poor staff performance.

According to Dahiya \& Luthra (2015) clear communication from company leadership, both understanding and relaying information, ensures that underlying company problems can be rectified and aid in strengthening staff trust in company leadership. 55\% of respondents believe that leaders at 
Company X do not mentor and coach staff that underperform. $30 \%$ of respondents indicate that leaders at Company $\mathrm{X}$ coach and mentor staff who underperform.

Eliadis (2016) states that coaching leadership styles lead to better cohesion between all staff and builds a belief system in company leaders which in turn increases not only staff morale but staff performance.

\subsection{Centered on Questions Impacting on Staff Behavior}

$50 \%$ of respondents disagreed to company leaders never embarrassing subordinates. $30 \%$ of respondents indicated that company leaders never embarrassed staff. According to Eliadis (2016) skilled leaders, especially those who coach and mentor, refrain from breaking down followers and staff in any way that could be detrimental to their overall performance. $48.3 \%$ of respondents did not believe that company leaders accepted responsibility for their mistakes, with $26.6 \%$ of respondents indicated that leaders at Company $\mathrm{X}$ accept responsibility for their mistakes.

Shi \& Ye (2016) state that responsible leadership builds internal trust within the company. This trust allows for employees to grow and create a desire to invest more time in the company. Irresponsible leadership have the opposite effect. $35.1 \%$ of respondents believed that company management did not provide benefits to staff members based on personal relationships. $51.7 \%$ agreed that company leaders did provide benefits based on personal relationships. According to Darioly \& Riggio (2014) leaders that practice nepotism dramatically decrease staff motivation and overall performance while cultivating the desire to gain factor based on social factors as opposed to performance based factors.

\subsection{Centered on Questions Impacting Leadership from Staff}

$18.3 \%$ of respondents disagreed to varying extents that company leaders expect complete obedience from staff. $65 \%$ of respondents agreed that leaders at Company X expect complete obedience from. Dahiya \& Luthra (2015) described leadership communication as understanding what staff and followers want as well as incorporating that into a mentoring and coaching leadership style to ensure staff performs optimally.

$18.4 \%$ of respondents feel that company leaders will not punish staff who disobeyed their leaders, whereas $64.9 \%$ of respondents agreed to varying levels that Company $\mathrm{X}$ will punish disobedient staff. According to Eliadis (2016) a leadership style based on force and punishment as opposed to understanding, mentoring and coaching can have a ripple effect throughout a company and reduce staff morale, trust and performance when working towards a leader's goal.

$21.6 \%$ of respondents disagree on varying levels that company leader make all the decision on their own. 56.7\% of respondents agreed that leaders at Company X make all company decisions on their own. Cherry (2008) states that leadership styles through which decisions are made purely by a single leader without the consultation of staff, team members or other followers are a component of the paternal leadership style and reduces overall staff performance as staff are less likely to take the initiative and work for the benefit of the company without an order to do so.

\subsection{Centered on Questions Assessing Leadership Actions}

$25 \%$ of respondents do not feel pressured when working with company leaders, with $46.7 \%$ of respondents feeling pressured when working with company. Chandler (2009) states that tension within companies are caused by leaders when unethical or forceful leadership styles are practiced such as autocratic or paternal leadership styles.

$18.4 \%$ of respondents feel that company leaders don't expect loyalty outside of work where as $60 \%$ of respondents felt they did. Heifetz \& Laurie (1997) state that leadership expectations that pass outside of professional boundaries tend to create discomfort among staff, can lead to high staff turnover and result in a slow decline in overall staff performance.

\subsection{Centered on the Impact on the Working Environment}

$38.3 \%$ of respondents are not inspired by company leaders, where as $33.3 \%$ of respondents are inspired by company leaders. Makaske (2015) described devoted leaders as having an inspiring effect on staff performance and motivation within a company.

$46.7 \%$ respondents state that company leaders do not create a supportive working environment, whereas $26.6 \%$ of respondents agreed with the statement. Maierhofer \& Newton (2005) state that 
company leaders who have a disregard for company staff and operations result in work environments becoming detrimental to staff.

$43.3 \%$ of respondents feel that company leaders to not contribute to staff satisfaction, where as $25 \%$ of respondents agree with the statement. Eliadis (2016) further states that staff satisfaction can be derived from leaders who invest in their staff or followers. Proactive leaders within their companies contribute to a positive work environment.

\subsection{Centered on the Assessment of Leadership Dedication by Staff.}

$48.3 \%$ of respondents feel that leaders do not share their vision and mission with staff within Company X, whereas $25 \%$ of respondents feel that the vision and mission is shared with them with. Fitzsimons et al. (2014) states that company leaders who share their vision and mission aid in building cohesion within corporate environments and boost morale significantly.

$53.14 \%$ of respondents disagree with company leaders focusing on staff retention. $21.6 \%$ of respondents agreed with the statement. Muhangi (2016) states that due to the highly competitive nature of corporations, leadership is a key defining factor in influencing staff retention.

$43.3 \%$ of staff disagrees with company leaders at Company $\mathrm{X}$ believing in staff mentorship to increase overall performance, whereas $35 \%$ of respondents agreed with the statement. Khan \& Nawaz (2016) state that effective leadership styles will cultivate growth through mentorship, which in-turn will increase overall staff performance.

\section{CONCLuSion}

The paternal leadership style exists within Company $\mathrm{X}$ as is common within Vietnamese companies. The leadership style practiced at Company $\mathrm{X}$, according to the primary research, sections A through $\mathrm{F}$, indicate that the practiced leadership style has caused negative staff perception, leadership actions are frowned upon, leadership expectations are high without providing any support, leadership behavior is based on nepotism, leadership dedication towards staff are lacking and all this has created a negative working environment in which staff morale and performance both are impacted negatively. During this study an overview of the LSP at Company X has been provided. The effects on staff performance have been measured and quantified.

Based on the findings in the research, clear information has been provided in order for other companies in Vietnam to avoid this leadership style and understand its impact on staff performance, as well as making Vietnamese Nationals, Expats and investors aware of the impact of the PLS on Vietnamese work culture.

\section{REFERENCES}

[1] Dang, C. (2017) Leadership in Vietnam. Report. Kouvola: Business Management, South-Eastern Finland University of Applied Sciences.

[2] Be, N. (2013) Vietnamese Politics: China - Vietnam Relations and TPP. Report. Tokyo: International Political Economy, Graduate School of Public Policy MPP/IP.

[3] Meyer K., Nguyen, H. and Nguyen, T. (2015) Foreign Direct Investment within Vietnam. In Researchgate [online]. Available from: https://www.researchgate.net/publication/266495656_9_Foreign_Direct_ Investment_in_Vietnam [Accessed 06 August 2018].

[4] Boer, K., Cheng, B., Chou, L. and Tsai, C. (2013) Paternalistic Leadership in Four East Asian Societies. https://www.researchgate.net/publication/258167116_Paternalistic_Leadership_in_Four_East_Asian_Soci eties [Accessed 06 August 2018].

[5] Makaske, I. (2015) The effect of leadership behavior on work climate and team effectiveness [online]. Available from: https://essay.utwente.nl/67485/1/Makaske_BA_faculty.pdf.pdf

[6] Dahiya, R. and Luthra, A. (2015) Effective Leadership is all About Communicating Effectively: Connecting Leadership and Communication. Haryana: SRM University

[7] Eliadis, A. (2016). Coaching as a Leadership Style: The perceived Benefits of a Leader Adopting a Coach Approach Leadership Style. Dallas: University of Texas

[8] Shi, Y. and Ye, M. (2016) Responsible Leadership: Review and Prospects. Guangzhou: School of Management, Jinan University.

[9] Darioly, A. and Riggio, R. (2014) Nepotism in the Hiring of Leaders. Neuchâtel: University of Neuchatel.

[10] Cherry, K. (2008). Leadership styles and benefits. Paris: University of Paris 
[11] Chandler, D. (2009). The Perfect Storm of Leaders' Unethical Behaviour: A Conceptual Framework. Virginia: School of Divinity, Regent University

[12] Heifetz, R and Laurie, L. (1997). The Work of Leadership. Boston: Harvard Business School

[13] Maierhofer, N. and Newton, C. (2005). Supportive leadership and well-being: The role of team value congruence. Brisbane: Queensland University of Technology

[14] Fitzsimons, D., Martin, J., McCormack, B. and Spirig, R. (2014) The importance of inspiring a shared vision [online]. Available from: https://www.fons.org/Resources/Documents/Journal/Vol4No2/IPDJ_ 0402_04.pdf_[Accessed 20 October 2018].

[15] Muhangi, B. (2016) Leadership style and staff retention in organisations. Uganda: Mountains of the Moon University.

[16] Khan, I. and Nawaz, A. (2016) The Leadership Styles and The Employees Performance: A Review. Pakhtoonkhwa: Gomal University

Citation: Jared Potgieter, Christo A. Scheepers. "Measuring the Impact of the Paternal Leadership Style on Staff Performance at Company X, Vietnam" International Journal of Managerial Studies and Research (IJMSR), vol 7, no. 4, 2019, pp. 96-100. doi: http://dx.doi.org/10.20431/2349-0349.0704013.

Copyright: (C) 2019 Authors. This is an open-access article distributed under the terms of the Creative Commons Attribution License, which permits unrestricted use, distribution, and reproduction in any medium, provided the original author and source are credited. 